\title{
A dança na escuta do corpo do ribeirinho: o Proformar valorizando os profissionais da educação na Amazônia
}



Maria do Céu Sampaio*

\section{Resumo}

O artigo versa sobre a escuta do corpo e da expressão gestual do ribeirinho que são parte do contexto sociocultural amazônico (Brasil). Espalha insigts de gestuais expressivos que, certamente, enriquecerão o conhecimento acumulado pelas pesquisas em dança no Brasil. Envolve a dança articulada ao Programa e Educação a Distância - Proformar, investindo na interação dança-homemambiente no contexto amazônico, uma parceria dança e tecnologia, promove mudanças no cenário pedagógico articulado ao estudo da natureza da arte, num processo interdisciplinar.

Palavras-chave: transdisciplinaridade; dança; educação a distância (EAD); Amazônia; metodologia.

\section{Abstract}

This thesis addresses the theme of dance as communication and space, studying the habitat of the circles in rehabilitation of movement and gestural expression of individuals who are part of a sociocultural Amazon (Brazil). Research spreads insigts expressive gestures, which will certainly enrich the knowledge accumulated by research in dance in Brazil. Involves actions through the dancing, that can be applied in the Distance Education Program which is known as Proformar, investing an interaction between dance-human beingenvironment, in Amazônia context, dance and technology, in this manner

\footnotetext{
* Maria do Céu Sampaio, mais conhecida como Lia Sampaio, é professora especialista em Arte-Educação. E-mail: liasampaio.danca@gmail.com
} 
giving emphasis to the humanity and its intellectual and cognitive growth. In consequence of this, promoting changes in the pedagogical scenery and in the political-cultural action applied to the study of the nature of art, in a interdisciplinary process.

Keywords: interdisciplinary; dance; distance education; Amazônia; methodology.

O corpo retira dos pés a essência da força matriz, tocando o solo e ampliando espaços, promovendo uma dança capaz de contar história numa relação corpo e natureza. Convidando a ler a expressão e a atmosfera que são reveladas (Maurice Bejart, 1974).

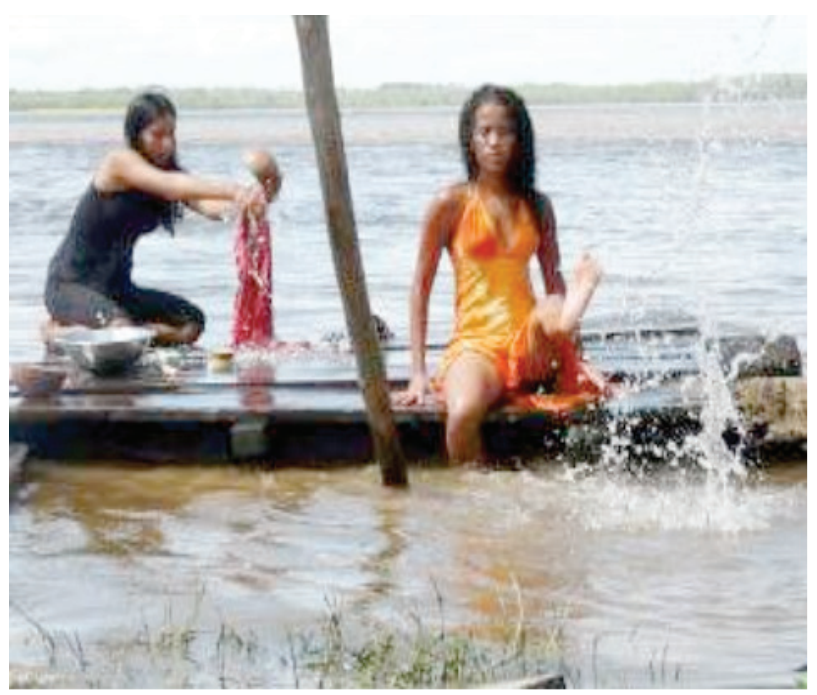

Figura 1 - Vivências em espaços do cotidiano.

Foto - Meireane Carvalho, 2008.

O artigo conta de um processo que proporcionou novas perspectivas de aprendizado das falas do corpo, contextualizando um discurso próprio por meio da dança e se utiliza de uma engenharia de abordagem da ciência e tecnologia, por intermédio de pessoal qualificado, valendo-se de recursos tecnológicos e procedimentos didáticos de ponta, com atuação profissional 
em rede de trabalho técnico, científico, pedagógico e comunicacional. Liga o sujeito ator a uma central interativa por um sistema mediado pela TV, de forma presencial, gerando uma cadeia produtiva entre o saber e o aprender amparado por uma plataforma tecnológica que cria conexões entre o real e o virtual sem perder a pertencência de sala de aula.

A dança contribui para alimentar essa rede, estabeleceu relações sociais com a cultura do lugar, numa mediação pedagógica com o sujeito ator, escola e sociedade. Compartilhou experiências impregnadas de informações pela arte e sensibilizou profissionais da educação que não precisaram sair de seu lugar de origem, nem abandonar sua história, sua cultura, seu pertencimento, transformando a floresta numa grande geradora de conhecimentos num harmonioso fluxo do saber.

As propostas têm relação intrínseca com a música, com o movimento, em perfeita conexão com a metodologia evidenciando o respeito e liberdade de ação e movimento compartilhados com outros saberes, que se exprimem em expressão pelo rastro do gesto; encontram pessoas e histórias em rito de passagem determinando momentos de libertar o corpo de qualquer concepção preestabelecida de forma, de movimento e de gesto. Como bem disse o mestre Klauss Vianna, apaixonado que foi pela dança, para que desperte o desejo permanente, de investigação perante a dança e a arte que, para mim, se confundem com vida (VIANNA, 1990: 9).

Teve como foco o corpo religando história e cultura num deslumbramento, em comunhão com o ambiente e seus pertencimentos; com a história de seus atores, valorizando mais processos que resultados, por meio de atividades históricas e evolutivas, sociais, antropológicas e cognitivas favorecendo as populações da floresta, tomando emprestada cultura e a arte viva, tingindo o espaço pela cor do gesto.

Uma relação paralela que se desenvolveu entre tempo e espaço, de forma interdisciplinar, no uso do corpo como expressão, como uma teia, a dialogar com vozes e falas, articuladas a outros saberes, numa malha complexa entre ética e amor, promovendo "pertencência e historicidade, exigindo novas maneiras de reaprender", sintetiza Morin, com muita propriedade (2004: 74).

Edgar Morin (2004) defende que a finalidade ética acontece-nos a partir de certo patamar de intensidade na participação, na excitação, no prazer, 
estado que pode ser alcançado na relação com o outro, na relação comunitária, na relação estética. Para nós, dançadores, a ética de trabalhar o corpo do outro. Uma malha intrincada entre valores que permeiam esse processo, dotado de uma epistemologia própria à luz de uma abordagem filosófica. Diz o autor: "é vivido como alegria, embriaguez, comemoração, gozo, volúpia, delícia, encantamento, fervor, fascinação, beatitude, deslumbramento, adoração, comunhão, entusiasmo, exaltação, êxtase" [...] "é, sobretudo, viver poeticamente a vida", proporcionando prazer articulado a saberes e sentidos de dizer e fazer dança, vivido com alegria a cada descoberta. É procurar articular tempo e espaço entre o gesto da palavra dita e o gesto desenhado no fluxo histórico, no discurso do corpo na construção da dança como campo de saber (2004: 202).

Assim, o estudo da dança aqui apresentado neste artigo segue um itinerário semiótico em recortes geográficos, numa trilha ambiente de pertencimento do ribeirinho que ela faz no contexto social, onde signos são decodificados em outros signos, dizem respeito a imagens, defendem valores e são interpretados por meio do discurso do corpo de forma dual, ou seja, interna e externamente. Em outros termos, o que acontece no corpo repercute no ambiente (onde estão, é claro, outros corpos) e vice-versa. Tudo pode ser interpretado no ato, quando aparece, quando se dá a ver. São valores que fazem parte da geografia perceptiva. É ver, observar, sentir, conceituar e dar significados às imagens percebidas.

Os atores envolvidos - profissionais voltados para a educação - devem ter noções dos princípios básicos, de onde serão extraídos seus conceitos interpretativos nas esferas sociais e humanas. Devem prosseguir expandindo nos seus rumos, na ideia de processo e inovação, buscando favorecer uma exploração criativa, sobretudo, com ênfase no espaço, sem perder a visão do todo, utilizando criatividade e flexibilidade, provocando um novo olhar para a dança no contexto cultural, social e ambiental.

Perceberemos, então, essa herança cultural influenciando comportamentos, construindo novos abrigos e novas referências, em todos os movimentos realizados pelos ribeirinhos e seguiremos a sua trilha corporal, em traços culturais comuns do seu cotidiano. Manifestações expressivas serão observadas. As sociais, as religiosas e artísticas, os repertórios orais e corporais, ou seja, os gestos, hábitos, passagens, reprodução e preservação de saberes. Um processo vivo de pensamento numa tríade que envolve signo, 
objeto e interpretante, aberto aos sentidos que constroem as bases de uma estética própria e complexa em ritmos que se repetem, em ostinatos, porque repetição é um valor estético das suas tribos, mesmo que representados por diferentes etnias.

O corpo é propício a experimentações. Derramam-se em imagens que nos levam ao processo de projeção do nosso imaginário, usando livremente o peso, o volume do corpo num tempo lento das águas dos rios que correm quase imperceptíveis, sereno, calmo e ao mesmo tempo forte, simulando a força bravia da sua energia, garante Katz (2005), que complementa dizendo: "a dança é o pensamento do corpo e processa conhecimento".

E mais:

Quem observa o corpo, percebe que nele ocorrem tanto aprimoramentos graduais quanto emergências (...). A habilidade que se repete melhora gradualmente através do treinamento que burila o exercício. No entanto, eventualmente, irrompem novas circuitações, que surpreendem o controle (...). Isto ocorre muito provavelmente porque um processo de repetição não se dá sem minúsculas diferenças entre cada repetição. E a repetição com essas minúsculas diferenças, a certa altura, produz uma diferença que se nota (KATZ, 2005: 39).

No entendimento artístico desse ator-ribeirinho e na sua capacidade de expressão pessoal, os símbolos falam uma linguagem universal, imagens, gestos e sinais se apresentam em espaços vívidos e espaços percebidos como ações genuinamente humanas, no entanto sofrem nuanças e inflexões que variam de acordo com experiências individuais e a geografia perceptiva do lugar.

A geografia da percepção, segundo Santaella (2005), está ligada à fenomenologia e à semiótica. Afirma a autora que a semiótica nasce no coração da fenomenologia. Por isso mesmo, produzem discursos próprios, portadores de tradições e, ao mesmo tempo, cheios de referências do ambiente ao qual pertencem. Sua trilha se dá no construir formas livres e espontâneas, permitindo a interpretação de um sentimento pessoal, momentâneo em resposta a estímulos de códigos digitais. E, ao mesmo tempo, descrevem um pensamento estético, por meio de gestos levados por caminhos que favorecem 
o contato com outras culturas, outros corpos, outros lugares, por opção de preservar alguém no espaço em manifestações antagônicas, ao mesmo tempo opostas e complementares.

$\mathrm{O}$ ator vivencia os fenômenos no entorno que se apresentam em forma de signos que são percebidos e decodificados em gestos. Delineiam-se em recortes interpretativos tirados de elementos de contexto político, social e cultural na mesma linha, onde a dança torna-se ponto de encontro entre imagem, tempo, espaço e mídia, e formam-se ressonância no meio e entre informações, adquirindo contribuições emprestadas de outras culturas: as circunvizinhas.

A incorporação de elementos pertencentes a essas culturas, que deságuam em trilhas sobre as quais emergem como padrão, deixa uma impressão profunda nos gestos dos ribeirinhos direcionando a atenção rumo à tendência do étnico e são considerados como elementos exóticos. São alma e corpo que operam por meio de estados de movimento e repouso; velocidade e lentidão, assim como a passagem das águas do rio. Tudo fazendo parte do ambiente. Contudo, insurgem de um movimento de liberdade, por esse processo de contribuições emprestadas, de um gestual de manifestações estéticas e incorporações desses elementos exóticos escutados naturalmente, numa trilha única e pessoal que vaza como um casamento entre culturas.

Segundo Vianna (1990), "todo o nosso ser corporal percebe e distingue imediatamente as coisas no nosso meio ambiente" e rapidamente percebemos, vemos, ouvimos e sentimos essas manifestações corporais, atentos a essa consciência de nossas emoções. Prossegue afirmando: "à medida que nosso corpo abre caminho através do tempo e que o mundo circundante se transforma e nos acene com novas situações e estímulos", [...] "podendo então dizer que a nossa imagem é a imagem de nosso corpo". Porque o corpo faz parte do mundo; logo, isto é, da Natureza Humana (ApudVIANNA, ANGEL e POPE, ALICE). ${ }^{1}$

Uma complexidade de sobreposição de ritmos e movimentos, nesse vasto espaço investigativo e amazônico, em todas as ações e fenômenos ali instalados. Pode ser observada, por exemplo, no momento em que a mulher ribeirinha lava roupa no jirau, ${ }^{2}$ trata e tica ${ }^{3}$ o peixe, entra e sai da canoa, mexe a farinha, extrai o tucupi $i^{4}$ no tipiti. ${ }^{5}$ (Figuras 2 e 3). 

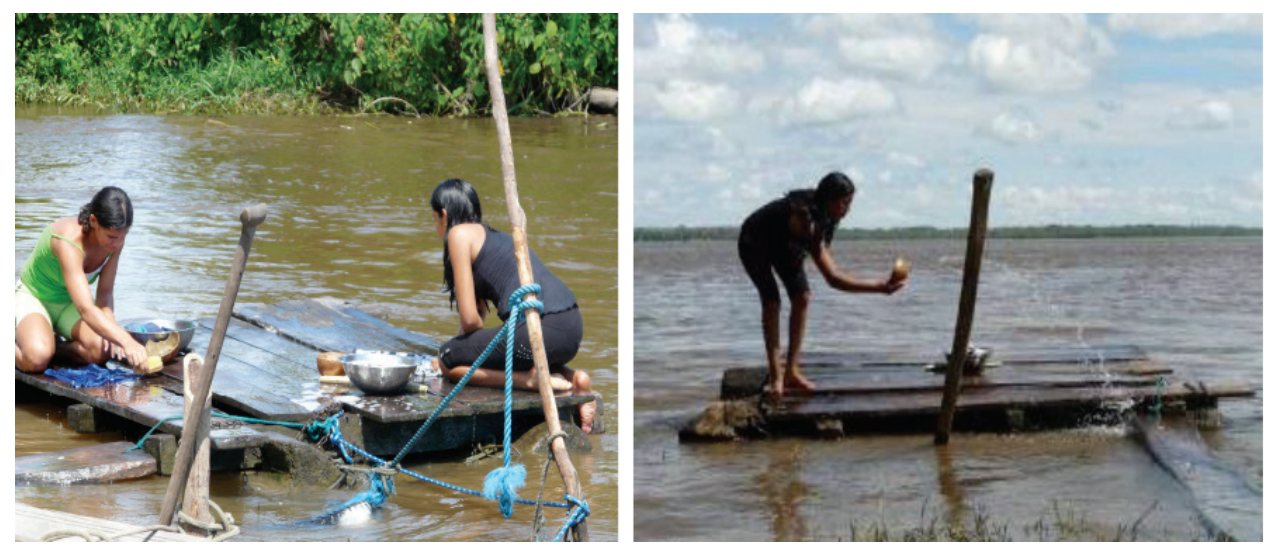

Figuras 2 e 3 - Manacapuru, investigações e vivências em espaços do cotidiano.

Foto - Meireane Carvalho, 2008.

Segundo Santaella (2005), são elementos que representam o objeto e transmitem informações que vão produzir mensagens claras e sensações perceptivas, de modo próprio, como apelo cinestésico, ${ }^{6}$ promovendo uma escuta interior que é responsável pelo equilíbrio e o reconhecimento postural em ações práticas cotidianas. Referem-se a resultados interpretativos ao qual todo ator, aqui representado pelo ribeirinho, está destinado a chegar se a investigação sobre o signo for internalizada, possibilitando a 'escuta do corpo' que é acenado por meio da vida coletiva de uma cultura que assimila pilares estéticos como herança. É o rastro do gesto - expressão usada por Santaella, muito própria para o que tratamos aqui, ou seja, o gestual cômodo que busca na sua trilha correlações entre performance e memória pelos sentidos. Ganha poder sugestivo da mensagem em detrimento de sua função laboral, como referencial explícita ou de sua significação abstrata e surge, então, o brilho, a cor e a textura como qualidade inconfundível (SANTAELLA, 2005).

A diversidade de imagens da natureza alimenta a imaginação interligando de forma transdisciplinar objetos que revelam saber, acrescidas de configurações variadas do fazer humano. O signo provoca ações ativas no estado corporal do ribeirinho - dançador e figuras ganham vida própria atravessando o corpo, construindo ideias, brincando entre espaço e tempo em fluxo contínuo numa releitura que permite explorar mais essa escuta do ambiente e provoca, de alguma forma, ganhos conceituais importantes. Vista por Vianna como "suas reações extraordinariamente agudas para tudo o que 
é de interesse no seu ambiente" (1990: 70).

Funcionam como molas propulsoras, na vida cotidiana do ribeirinho, despertando responsabilidade ética como um bom começo para descoberta de que a natureza já contém em si eloquência própria numa simples qualidade de sensação, de percepção e de sugestão que permitem ir além, é o elemento básico percebido e escolhido, ou seja, o tema das articulações gestuais que invadem o campo cognitivo em diálogos corporais, tornando os sentimentos parceiros de uma dança que traz nas batidas do coração um ritmo natural e na respiração a qualidade de movimentos que constroem um discurso próprio e espontâneo.

Dessa maneira, atividades realizadas por meio da dança se tornam responsáveis pela dimensionalidade que é entendida pelo corpo do intérprete criador - aqui representado pelo corpo do ribeirinho. Percebemos aí que o gesto está presente no ambiente, são ações que têm cor e têm cheiro, nascidas dessas informações.

Setenta (2008) diz que

A organização corporal da fala da dança faz das informações trocadas, entre corpo e ambiente, o seu material do mundo. Registros, traços e vestígio de vida; histórias de vida. Do contato que se estabelece entre as informações que vêm de fora com as informações existentes em um corpo, ocorre um movimento de reorganização, que desencadeia a produção de outras informações (2008: 41).

Essas informações são interpretadas pelo corpo, invadem outros afazeres que fazem parte do dia a dia do povo da floresta provocando experiências novas que levam a descobertas de novas possibilidades de organização no estado corporal e ganham valores estéticos, podendo estruturar "falas construídas, estruturadas e organizadas como um discurso de dança”, diz Setenta, brotando, então, temas imaginários, como afirma Foucault:

Certamente, há a experiência imediata, os temas imaginários que carregam e reconduzem sem cessar crenças sem memória; mas talvez não haja erros em sentido estrito, porque o erro só pode surgir e ser decidido no interior de uma prática definida; em contrapartida, rondam monstros 
cuja forma muda com a história do saber (FOUCAULT, 1970).

Imaginem uma casa habitada, cheia de espaços entre paredes e jardins, objetos carregados de significado, assim é o nosso corpo. Ambiente perfeito onde habitantes se misturam entre os espaços e flutuam os nossos medos, as ideias, os amores, a raiva e os fantasmas. É habitado por monstros, crenças e memórias, cheia de vãos e desvãos carregados de crenças, de preconceitos, de ideias, de medos e sustos, pudor e significados. Logo, é essa casa, que é o corpo, que é a nossa morada, somos nós, que, segundo João Batista Freire, é "habitada pelo sensível e pelo inelegível que convivem sob o mesmo teto e estarão, inevitavelmente, sempre em conflito necessário”. Conflitos que circulam e navegam pelo corpo explorando esses vãos, levando mensagens que abordam como imagens e revelam acontecimentos que chegam intuitivamente controlados pela razão como resultado transitório que desenham variados caminhos (FREIRE, 1991: 145).

Pode ser decifrado como a matriz cinética do pensamento do corpo, diz Katz. Aparece em níveis de complexidade presenteando-se na densidade do corpo, numa tensão manifestativa; é, portanto, tanto a escuta como a visão onde o movimento se dá a ver. A dança se faz assim. É como o curso dos rios por onde o sempre novo emerge cada vez que o movimento se dá a ver. A “dança é quando e depois e descobertas infiltram comportamentos e fica parecendo cada vez mais com o rio" (KATZ, 2005: 153).

Estabelecem conexões sociais e culturais entre percepção - ação e se alimentam e alimentam o processo de forma simultânea. Parafraseando Katz, "é corpo e mente numa cadeia de significados" impregnados de informações que são codificadas, percebidas e sentidas passo a passo - e o corpo copia plasticamente essas histórias decifrando um mundo aberto, produtivo e inventivo, percorrendo diferenças a cada momento incorporado a um processo dinâmico, onde o "trânsito e o fluxo jamais acabam" (1994: 83).

Afirma a autora que

a hipótese de que o corpo, tal como o cérebro, também possui um pensamento, permite que se desloque a ênfase usual do entendimento da dança. Pensamento, aqui, deve 
ser entendido como uma ação movida por um propósito (KATZ, 1994: 84).

E complementa a autora:

A organização corporal da fala da dança faz das informações trocadas, entre corpo e ambiente, o seu material do mundo. Registros, traços e vestígio de vida; histórias de vida. Do contato que se estabelece entre as informações que vêm de fora com as informações existentes em um corpo, ocorre um movimento de reorganização, que desencadeia a produção de outras informações. O movimento nascido dessas informações pode tomar a forma de falas construídas, estruturadas e organizadas como um discurso de dança, onde, a cada nova situação do estar no mundo, já outras informações se configuram (KATZ, 2008: 41).

Esse propósito, de que fala Katz, está na trilha que discorre entre linguagens verbais e não verbais, do corpo do ribeirinho em conexão com a consciência perceptiva sobre conteúdos inseparáveis da sua personalidade. Presentes em ações capazes de explodir criativamente, proporcionando "uma nova escuta e uma escuta velha" que Maria Fux chama de "ideia do espelho interior", uma escuta e um contato consigo mesmo para descobrir as próprias respostas (Figura 4 e 5).
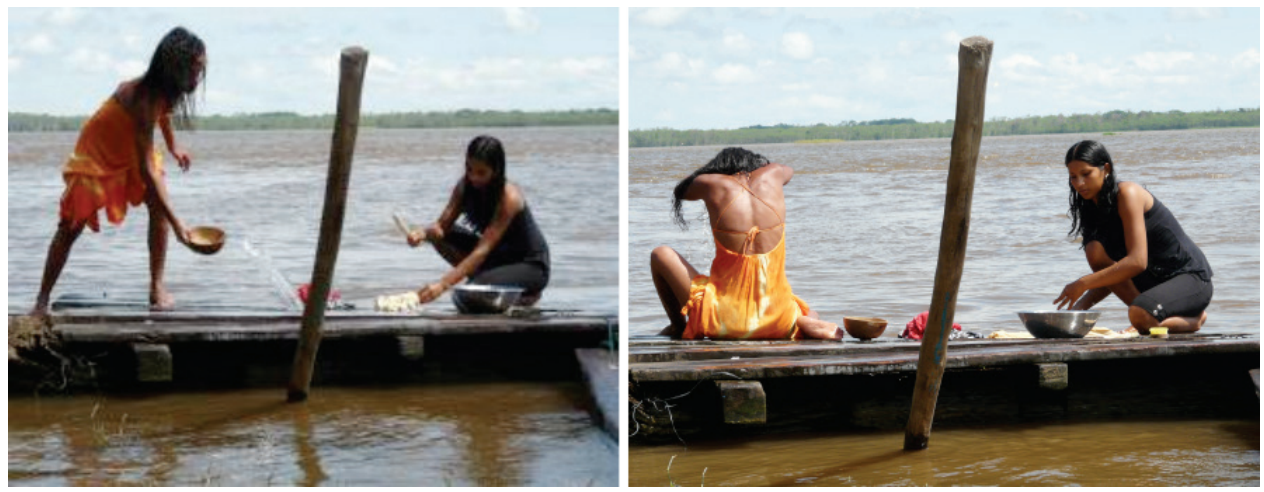

Figuras 4 e 5 - Vivências corporais em espaços alternativos.

Foto - Meireane Carvalho. Manacapuru, 2008. 


\section{O lugar da dança sob a luz da escuta poética - uma dança fenomenológica}

Então, escutar é deixar-se invadir pelo real acontecendo. Por isso, não há fora nem dentro. Talvez fique mais claro, se for possível, que um outro modo de escuta do real é a visão. Ver como escuta poético-onto-fenomenológica é deixar o real se tornar, se doar como presença onde está incluído tanto o que se vê como quem vê e a própria luz e a própria clareira onde tudo isso acontece. É deixar eclodir o 'sendo', a realidade se realizando (Fernando Pessoa, 1888-1935).

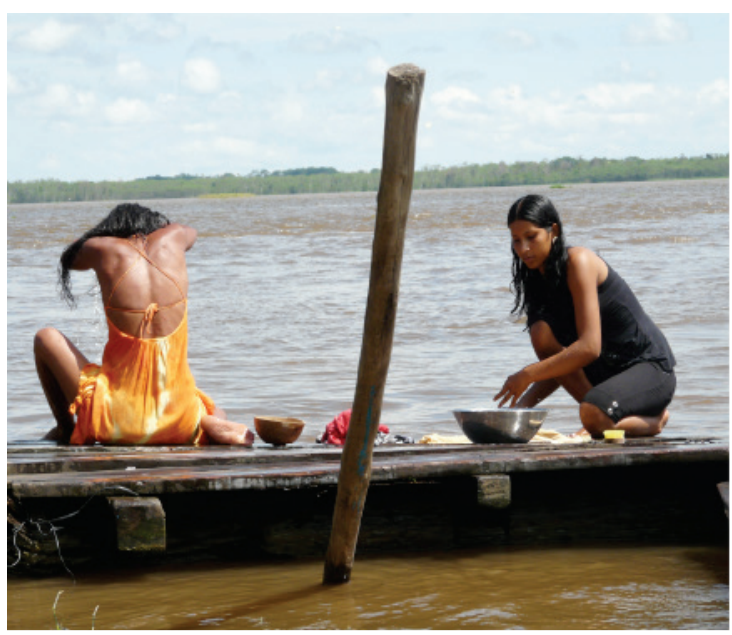

Figura 6 - Vivências corporais em espaços alternativos. Foto: Meireane Carvalho. Manacapuru, 2008.

Devemos ter em mente que falar de 'escuta poética' implica falar de muitos caminhos e ouvir muitas vozes, aberto e atento ao pertencimento, presentes nas percepções e sensações voltadas para o ambiente. É o corpo tomando o ambiente como seu. Estabelecendo relações de pertencimento entre informações em formas de conceitos de repetição e criatividade. O corpo num sistema aberto que recebe e seleciona informações e o torna apto a dialogar em seu meio ambiente, que é de seu pertencimento.

Prigogine defende uma escuta poética silenciosa. Fala de uma escuta poética como comunicação que acontece de forma fenomenológica estabelecendo relações mística, com a poesia e a música, para compreender 
melhor os fenômenos da Natureza. Uma escuta poética que circula por todo o corpo, promove estímulos pelo uso de imagens, formas, cores e variados ritmos numa relação com o universo de significados, em conectividade com um espaço aberto, produtivo e inventivo, em diálogos, reunindo falas de forma transdisciplinar que religam a subjetividade no pensamento do corpo (PRIGOGINE, 2002).

Passeia por caminhos de passado e de futuro. Incorpora valores, perceptivos, e possibilidades, capaz de ouvir o apelo da natureza. É “colocarse na escuta da natureza", diz Prigogine, [...] "capaz de respeitar a natureza que se faz falar". É respeitar as diferenças num processo aberto entre a "história dos homens, de suas saudades, de seus saberes" (PRIGOGINE, 1986: 189).

Partindo do pressuposto de que no silêncio podemos escutar o som do próprio corpo e realizar movimentos ondulantes, linhas abertas e fechadas, descobrindo uma vasta possibilidade de lidar com o desconhecido, liberto de paradigmas sociais, culturais, raciais, éticos, abertos às diferenças. $\mathrm{O}$ corpo torna-se visível, mostra-se conectado a uma evolução tônica e corporal, com enorme carga afetiva de incertezas e questionamentos, ligados ao cognitivo, "dançando de dentro para fora" e reconhecendo o corpo que se utiliza da dança e movimento para melhorar e transformar pessoas que vão expressar o mundo oculto a partir da escuta do seu corpo, que Fux trata como 'uma nova escuta' (FUX, 1998).

A dança é o signo da cognição que o corpo revela como usuário e proprietário daquilo que escuta e constrói por meio de imagens que se esparramam pelo espaço imprimindo formas, fazendo travessias num fluxo contínuo, desencadeando movimentos em arranjos infinitos, que contam histórias. É mediada por um veículo de comunicação, portanto revela uma metodologia complexa construtivista fundamentada em conceitos e princípios, cujo modo de realização se dá na escuta do fazer, do dizer, do agir e do ser, de forma transdisciplinar que se põe à disposição do corpo. Transita pelo meio ambiente processando conhecimentos, de forma ininterrupta, reconhecendo o ambiente como seu; troca informações; sempre sujeito às modificações, apreende imagens que são construídas e des-construídas interagindo com o meio ambiente.

Oferece-nos uma nova visão da natureza e da realidade que se serve de novos conceitos para sua aplicabilidade no processo. Aberta a diálogo com 
a arte, a literatura, a poesia e as experiências espirituais. Promovendo uma liberdade única que busca investigar, compartilhar com outros saberes. A liberdade de expressão.

Nesse momento, o espírito inventivo torna-se cúmplice da sua historicidade, expandindo-se, impregnando o seu corpo com material de arquivo detentor dessa memória gestual, cotidiana, inserida no meio ambiente. Você tem de se situar no espaço e tempo como personagem, no processo. O importante é que esse espaço e tempo não sejam separados, existindo por suas igualdades e diferenças, dinâmicas e dimensões, para as contradições, para a colaboração mútua e para a criatividade, coabitando a própria diversidade, impregnado de informações priorizando o acesso ao conhecimento socialmente produzido. Afinal, a dança é mantida pela possibilidade da coexistência, está vinculada aos pressupostos da sua área, é construída nos acontecimentos do expediente cotidiano (VIANNA, 1990).

São gradualmente incorporados à linguagem do dia a dia, passando por rituais de todo tipo, ajustando-se a movimentos dinâmicos, interagindo a outras linguagens e outros vocabulários, tornando-se inclusivos ao que é diferente, ajustando-se ao que chega de outras partes, (re)configurando, criando, assim, uma grande quantidade de variáveis numa liberdade de arranjos de movimentos, onde o movimento pode ser continuo e inúmeras modificações podem ser imaginadas.

O próprio espaço torna-se suscetível ao movimento com a aproximação orientada ambientalmente, onde, segundo Cunningham, "cada ato faz a sua história" (Figura 7). O autor defende e apresenta uma dança com espaço descentralizado, no qual não existem pontos fixos no espaço, qualquer lugar pode ser um espaço cênico, onde ações cotidianas podem ser exploradas em seu meio ambiente, isso significa desenvolvimento de diferentes formas de comunicação (CUNNINGHAM, 2004: 88). 


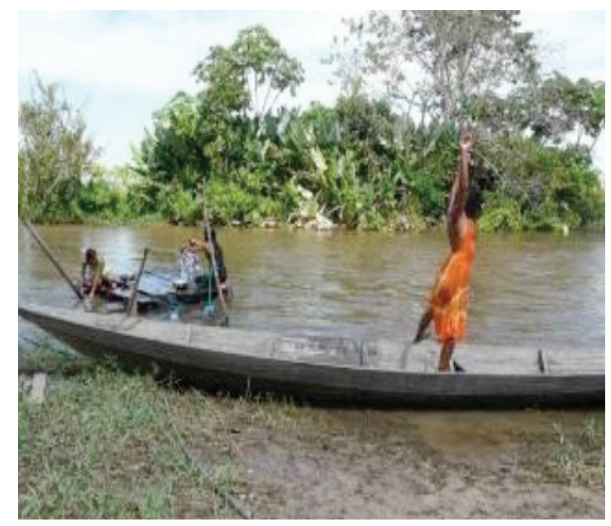

Figura 7 - Vivências corporais em espaços alternativos.

Foto - Meireane Carvalho. Manacapuru, 2008.

Com essa descentralização, ou seja, aberto a utilizar a gramaticidade do ambiente, criando novos jogos, novas regras, a fim de reorganizar a sua dança, o corpo ganha novas características, que são re-elaboradas no entendimento, gozando de inteira liberdade de expressão.

Vianna diz que

cada um de nós possui a sua própria dança e seu próprio movimento, original, singular e diferenciado, e é a partir daí que essa dança e esse movimento evoluem para uma forma de expressão em que a busca da individualidade possa ser entendida pela coletividade humana (VIANNA, 1990: 118).

Muitas vezes descentralizado, rompendo barreiras e, no entender de cada grupo, retirando formulações de fenômenos que a natureza e a vida proporcionam numa conexão que desliza no processo criativo, funcionando como eixo gerador no processo coletivo. A relação acontece entre cadeias semióticas, ou seja, ocorre em cada espaço num fluxo de passado, reescrevendo o presente e o futuro no lugar onde o movimento acontece. O sujeito/ator decifra ou reconhece, naquele momento, mensagens que estão diretamente ligadas à memória, à imaginação, à percepção, à linguagem, ao pensamento, elementos envolvidos com a experiência na construção do processo.

Tudo é construído socialmente e segue na trilha da escuta do seu corpo. O ator passa a viver para o momento. Momento, que Sandra Chacra, 
que se dedicou a estudar sobre o movimento, trata como dimensão temporal fenomenológica - aqui e agora, que pode ser entendida e compreendida tantas forem suas interpretações no processo de construção do conhecimento. Qualquer que seja o contexto sócio-histórico e código cultural trata a intenção como polo e divisor de águas no processo interpretativo (1991: 68).

Completamente em sintonia com os princípios de Morin, traz a lógica para as práticas cotidianas e faz dela um instrumental de esclarecimento e postura, apresentando reflexões para um comportamento ético responsável. Os elementos conceituais, culturais e a historicidade, apresentados aqui, promovem o envolvimento com diversos saberes. A ecologia da ação é, em suma, levar em consideração a complexidade que ela supõe, ou seja, o aleatório, acaso, iniciativa, decisão, inesperado, imprevisto, consciência de derivas e transformações (MORIN, 2004).

Vale a pena cruzar informações ensaiando passos novos no terreno do pensar. Interagindo com intuição e imaginação numa unidade necessária, inspirada em grandes cientistas, teóricos e filósofos. Desfrutar da iluminadora companhia desses grandes mestres do pensamento humano, traçando caminhos nesse estudo para uma reflexão que atue diretamente com o fazer e o agir, e, então, estar elaborando de forma diferenciada, um diálogo investigativo nessas paisagens recortes, entre tantas outras possíveis, atentos e perceptíveis a outros elementos presentes.

As verdades são construídas pouco a pouco, ampliando, assim, o seu universo de referências numa proposta que se fortalece a partir das experiências vividas em momentos de grande sensibilidade estética e fazem parte do processo. São traços em busca de bússolas de sentido, que marcam histórias e ideias dos clássicos e representam um fundamental instrumento de compreensão, interpretação, diálogo e crítica abertos ao espanto. Porque estar atento significa estar disponível ao espanto, aberto ao processo criativo. Sem medo, afirma Paulo Freire, quando diz:

Sem espanto não há ciência, não há criação artística. O espanto é um momento do processo de pesquisa, de busca. Essa postura de abertura ao espanto é uma exigência fundamental ao educador e à educadora. [...] O espanto, não o medo que ele tem nem é coisa de ignorante. O espanto revela a busca do saber (FREIRE, 1997: 30). 
O autor enfatiza a busca investigativa como um processo dinâmico que valoriza a interação do indivíduo com o ambiente e vê o professor/ator como sujeito que atua no processo de seu desenvolvimento. Nessa busca, o saber investigativo sobre a dança articulada ao Proformar, na escuta do corpo do ribeirinho, permitiu a valorização dos profissionais da educação na Amazônia, e foi possível promover o desdobramento da vivência pedagógica pluricultural na construção de uma identidade individual. A metodologia enfrentou todos os desafios propostos, os medos, e os espantos - aquele de que nos fala Freire, com uma única intenção: crescer, compartilhar, espantar-se e levar o outro a espantar-se também. Usar o corpo para fazer e dizer seus pensamentos num discurso organizado, pleno de significados, frutos desse espanto, porque $o$ espanto revela busca do saber (1997: 30).

A partir dessas considerações, podemos perceber um novo conceito articulando-se nos mais variados campos do conhecimento, demonstrando um diálogo entre espaço e tempo, corpo e movimento relacionando-se com o comportamento das pessoas, respeitando traços que são comuns. Isso quer dizer que estão sempre presentes em qualquer fenômeno da sociedade, e envolvem, satisfatoriamente, desafios advindos dessas novas ordens, enfrentando os riscos e medos com flexibilidade.

O artigo aqui proposto, nesse momento, é um convite e estímulo que deverá ser acionado - como um gatilho - marcadores cinestésicos importantes que permitam vivenciar certezas e incertezas, dúvidas e reflexões, investigações e inquietudes quando trata do respeito e liberdade de ação e movimento compartilhado na pessoa inteira que se exprime em expressão por meio do gesto seguindo os princípios do grande mestre Vianna (1990).

Nessa escuta do corpo do ribeirinho, a dança é entendida como um ambiente que se constrói a todo instante a partir de soluções que o corpo define e organiza no espaço do tempo real. Busca conexões com a trilha ambiente do ribeirinho evidenciada pela pesquisa do movimento no estudo do gesto, que, ao receber nutrientes adequados, abrem, despertam e evoluem assumindo atributos significativos, ou seja, corpo, memória e história sem preocupação com padrões estéticos, porque o ribeirinho, na construção das ideias, produz o pensamento do seu corpo no discurso próprio e natural e oferece uma dança pura que segue uma trilha de pertencimentos, que é circular, faz parte do seu hábitat e se apresenta onde o movimento se dá a ver. 
Valeu a pena traçar caminhos articulados com propostas revolucionárias de Klauss Vianna, Helena Katz, Maria Fux e outras vozes numa conceitualização para uma reflexão que interagiu diretamente com o ritmo, organização e desenho do gesto no espaço, para saber de forma perceptiva entender essa dança que religa subjetividade poetizando o corpo do ribeirinho.

Desse modo, a dança, protagonista dessa 'saga amazônica' e, também, mestre em poderes mágicos, foi enredo dessa história numa perspectiva da diferença, onde a singularidade possibilitou atores/leigos a vivenciarem experiências, na arte de dançar sem jamais abrir mão da simplicidade, por meio de sensibilização corporal, levando em conta as contingências históricas sem abandonar os ideais de pertencimento, seus nichos e sua cultura.

Foi ajustada ao seguimento educacional num processo diário e para a vida toda. Uma cadeia que funcionou integralmente sob a mira da percepção da informatização. Acendeu espaço para um corpo que pensa, que fala e que dança levando em consideração as dimensões territoriais, espaciais, sociais e culturais dos atores envolvidos e representou o brilho especial da disciplina Arte na Educação Infantil no Programa de Educação a Distância - Proformar, criado pela Universidade do Estado do Amazonas.

\section{Notas}

${ }^{1}$ Transcrição do manuscrito "Expressão Corporal" postado por Equilíbrio, Angel Vianna e Alice Pope, 2011.

2 Jirau - armação de madeira semelhante a estrado ou palanque para uso doméstico.

${ }^{3}$ Ticar - termo regional usado para preparar o peixe, ticando, ou seja, retalhando o peixe para fritar.

${ }^{4}$ Tucupi - espécie de molho feito com água de goma e pimenta - que acompanha pratos regionais.

${ }^{5}$ Tipiti - cesto cilíndrico de palha em que se põe a massa de mandioca para ser espremida.

${ }^{6}$ Cinestesia - termo utilizado para nomear a capacidade em reconhecer a localização espacial do corpo, sua posição e orientação, a força exercida pelos músculos de forma perceptiva. 


\section{Referências}

FOUCAULT, Michel. A Ordem do Discurso. 10. ed. Paris: Éditions Gallimard; São Paulo: Loyola, 2004; 1971.

FREIRE, Paulo. Educação e Mudança. Rio de Janeiro: Paz e Terra, 1982. - Pedagogia do Oprimido. Rio de Janeiro: Paz e Terra, 1987. - Pedagogia da Autonomia: saberes necessários à prática educativa.

Rio de Janeiro: Paz e Terra, 1996; 2000 (ed. especial 2007).

FREIRE, João Batista. De corpo e alma. São Paulo: Summus Editorial, 1991.

GREINER, Christine. O Corpo: pistas para estudos indisciplinares. São Paulo: Annablume, 2005.

KATZ, Helena. Um, dois, três. A dança é o pensamento do corpo. Belo Horizonte: Fid Editorial, 2005, p. 39.

MORIN, Edgar. O enigma do homem. Rio de janeiro: Zahar Ed., 1975.

- O Méthodo. La Méthode. La Connaissance de La Connaissance, Sevil. Ed. de Bolso, Coleção Points, 1990.

. Os sete saberes necessários à educação do futuro. Trad. Catarina da Silva e Jeanne Sawaya. 6. ${ }^{a}$ ed. São Paulo: Cortez, 2002.

. Alfredo Pena-Veja, Bernard Paillard. Diálogo sobre o Conhecimento. São Paulo: Cortez, 2004.

- A Cabeģa Bem Feita: repensar a reforma, repensar o pensamento. Rio de Janeiro: Bertrand Brasil, 2004.

O método 6: ética. Trad. de Juremir M. da Silva. Porto Alegre: Ed. Sulina, 2005.

NICOLESCU, Basarab. O Manifesto da Transdisciplinaridade. Coleção Trans., 2001.

OLIVEIRA, Alda. Revista da Abem, n. ${ }^{\circ}$ 14, vol. 14, p. 25-23, Porto Alegre, mar., 2006.

ASSOCIAÇÃO BRASILEIRA de Educação Musical. Educação musical $e$ 
diversidade: pontes de articulação, 2000, p. 25.

PRIGOGINE, Ilya. O fim das certezas: tempo, caos e as leis da natureza. Trad. Roberto L. Ferreira. São Paulo: Ed. Unesp, 1996; 2002.

SANTAELLA, Lúcia. A percep̧cão. Uma teoria semiótica. São Paulo: Experimento, 1998.

STRECK, Danilo; REDIN, Euclides; ZITZKOSKI, Jaime José (Orgs.). Dicionário de Paulo Freire. Belo Horizonte: Autêntica Editora, 2008.

VIANNA, Klauss \& CARVALHO, Marco Antônio de. A dança. São Paulo: Editora Siciliano, 1990. 